\title{
Evidence-based clinical tool for quantitative analysis of posture in children and adolescents with idiopathic scoliosis
}

\author{
Carole Fortin ${ }^{1,2^{*}}$, Debbie Feldman Ehrmann ${ }^{1,2}$, Farida Cheriet ${ }^{1,2}$, Hubert Labelle ${ }^{1,2}$ \\ From 10th International Conference on Conservative Management of Spinal Deformities - SOSORT 2013 \\ Annual Meeting \\ Chicago, IL, USA. 8-11 May 2013
}

\section{Background}

Correction of posture is an important goal of physiotherapy interventions in persons with idiopathic scoliosis (IS) to prevent scoliosis progression and to reduce morphologic deformities and their impact on quality of life. Currently, there are no clinical tools that globally quantify changes in posture attributable to scoliosis progression or treatment effectiveness.

\section{Purpose}

The goal of this study was to develop and validate a new clinical quantitative posture assessment tool among persons with IS.

\section{Methods}

We constructed a software-based program (2-dimensional (2D) tool) to calculate 23 posture indices (PI) representing frontal and sagittal alignment of body segments selected from a literature review [1]. The standing posture of 70 participants aged 10 to 20 years old with IS (Cobb angle: $15^{\circ}$ to $60^{\circ}$ ) was assessed on two occasions by two physiotherapists. Markers placed on several bony landmarks as well as natural reference points (e.g., eyes and ear lobes) were used to measure the PI from photographs with the 2D tool and to calculate 3-dimensional (3D) PI obtained from trunk reconstructions with a surface topography system. Frontal and sagittal Cobb angles and trunk list were also calculated on radiographs. The generalizability theory ( $\mathrm{f}$ and standard error of measurement - SEM) and Pearson correlation coefficients ( $r$ )

* Correspondence: Carole.fortin@umontreal.ca

${ }^{1}$ Centre de recherche, CHU Sainte-Justine, Montreal, Quebec, Canada

Full list of author information is available at the end of the article were used to determine reliability and concurrent validity, respectively.

\section{Results}

In the random design, 21 out of 23 of the PI had a good level of reliability ( $\mathrm{f} \geq 0.81$ ). The SEM values ranged from $0.9^{\circ}$ to $4.3^{\circ}$ and $2.1 \mathrm{~mm}$ to $8.5 \mathrm{~mm}$. Correlation between $2 \mathrm{D}$ and 3D PI was good to excellent for shoulder, pelvis, trunk list and thoracic scoliosis angles $(0.81>\mathrm{r}<0.97$; $\mathrm{p}<0.01)$ but fair to moderate for sagittal and thoraco-lumbar/lumbar scoliosis spinal indices $(0.30>r<0.56$; $\mathrm{p}<0.05)$. Correlation between 2D and radiograph spinal indices was fair to good $(-0.33$ to- 0.80 with Cobb angles and 0.76 for trunk list; $\mathrm{p}<0.05)$.

\section{Conclusions and discussion}

This 2D-imaging tool provides reliable [2] and valid [3] measurements of posture. This new evidenced-based tool may improve physiotherapy practice by facilitating posture analysis. Future longitudinal studies will determine its ability to monitor treatment effectiveness and change in posture over time in persons with IS.

\section{Authors' details \\ ${ }^{1}$ Centre de recherche, CHU Sainte-Justine, Montreal, Quebec, Canada. ${ }^{2}$ École de réadaptation, Faculté de médicine, Université de Montréal, Montreal,} Quebec, Canada.

Published: 18 September 2013

References

1. Fortin C, Feldman D, Cheriet F, Labelle $\mathrm{H}$ : Clinical methods for quantifying posture: a literature review. Disability and Rehabilitation 2011, 33(5):367-383. 
2. Fortin C, Feldman D, Cheriet F, Gravel D, Gauthier F, Labelle H: Reliability of a quantitative clinical postural assessment tool among persons with idiopathic scoliosis. Physiotherapy 2012, 98:64-75.

3. Fortin C, Feldman D, Cheriet $F$, Labelle $H$ : Validity of a quantitative clinical measurement tool of trunk posture in idiopathic scoliosis. Spine 2010 35(19):E988-E994.

doi:10.1186/1748-7161-8-S2-O27

Cite this article as: Fortin et al.: Evidence-based clinical tool for quantitative analysis of posture in children and adolescents with idiopathic scoliosis. Scoliosis 2013 8(Suppl 2):O27.

Submit your next manuscript to BioMed Central and take full advantage of:

- Convenient online submission

- Thorough peer review

- No space constraints or color figure charges

- Immediate publication on acceptance

- Inclusion in PubMed, CAS, Scopus and Google Scholar

- Research which is freely available for redistribution

Submit your manuscript at www.biomedcentral.com/submit
C Biomed Central 